Please quote as: Jahner, S.; Leimeister, J. M.; Knebel, U. \& Krcmar, H. (2008): A cross-cultural comparison of preceived strategic importance of RFID for CIOs in Germany and Italy. In: Proceedings of the 41st Annual Hawaii International Conference on System Sciences (HICSS 2008), Big Island, USA. 


\title{
A Cross-Cultural Comparison of Perceived Strategic Importance of RFID for CIOs in Germany and Italy
}

\author{
Stefanie Jahner Jan Marco Leimeister Uta Knebel Helmut Krcmar \\ Technische Universität München \\ Information Systems \\ Boltzmannstrasse 3 \\ 85748 Garching b. Muenchen, Germany \\ \{jahner ; leimeister; knebel; krcmar\} @ in.tum.de
}

\begin{abstract}
Purpose: Drawing from literature on innovation, strategy and culture the objective of this study is to explore the role of perceived potentials and perceived strategic importance on CIOs' perspective on RFID technology in two different cultural settings.

Methodology: Based on survey responses from 463 German and 157 Italian IT decision makers we analyzed the data with PLS structural equation modeling.

Findings: We show that perceived potentials of RFID influence the perceived strategic importance which positively influences CIOs' intention to invest in RFID. The composition of perceived potentials affecting the strategic importance of RFID differs significantly in both cultures. In Germany, potentials attributed to RFID are improving quality, automating manpower, reducing counterfeits, and improving customer-service. Italian CIOs value reducing stock inconsistencies, optimizing stock keeping, and improving customerservice as RFID potentials. Regardless of culture, findings show that company size hardly has impact on perceived strategic importance.

Originality/value: This research shows on a large empirical basis cultural differences in the perception of RFID in two countries using PLS.
\end{abstract}

\section{Introduction}

RFID is currently widely discussed throughout scientific and non-scientific media. Although it is not a new technology, the first publications date back to 1948 [25], it has only recently come to the awareness of the public. New auto-ID technologies, most notably RFID [37], have drawn the attention of many companies due to factors including: the need for more efficiency and security in supply chains, enhanced technologies, cost pressure, standardization initiatives, and prominent promoters such as Wal-Mart, Metro, and Tesco. When the Society of Information Management (SIM) conducted its last survey of IT executives, RFID was rated among the top 20 developments in application and technology [29].

The aim of this study was to explore CIOs' perspective on RFID technology in two different countries. The topmost research questions of this study therefore are:

1. What factors influence perceived strategic importance of RFID among IT decision makers?

2. Do cultural differences between German and Italian CIOs matter?

Using CIOs as a source of information, we investigated the role of perceived potentials and strategic importance in RFID, and how CIOs plan to act in regard to this issue. We want to shed light into the cultural differences in determinants (especially perceived potentials) and effects of perceived strategic importance of RFID.

\section{Related Research}

\subsection{RFID Technology}

RFID is a technology for automatic identification and data collection (Auto-ID). It allows an object or person to be automatically identified at a distance using an electromagnetic exchange [12, 42]. In comparison to other well-known Auto-ID technologies such as the 
barcode, RFID offers the following advantageous characteristics for the user [1]:

- Unique identification: Applying e.g. the "Electronic Product Code" (EPC) standards, RFID tags can identify classes of products as well as individual items.

- No line of sight: RFID tags can be read without direct line of sight even if the tag is covered, dirty or otherwise obscured from view.

- Bulk reading: If they are in range of a reader, multiple RFID tags can be read at the same time.

- Storage capacity: RFID tags can store significantly more information than just an identification number.

- Dynamic information: RFID tags with read-write capability allow information to be updated or changed whenever necessary.

Unfortunately, RFID is not yet a mature technology. There still are a number of issues that remain to be solved. For example:

- Effects of metal and liquid: Tags operating on radio frequency are not completely unaffected by materials in their close vicinity. Signals can be attenuated or detuned by metals or liquids.

- Multiple standards: In the past, several different frequencies and standards have been used for RFID solutions. Although the standardization organization EPCglobal has now designed a comprehensive new framework, it will take some time to establish.

- Amount of data: Collection and communication of enhanced object information inevitably leads to huge amounts of data. It is unclear how this data should best be integrated into the enterprise information systems. A common approach is to endorse ERP systems with RFID middleware. Moreover, enterprises still lack reasonable services and do not know what to do with the additional data.

\subsection{Improve Efficiency, Enable New Products and Services and Gain Competitive Advantage}

There is empirical [20, 28], conceptual [2] and simulational [26] evidence that RFID has the potential to accelerate, enrich, and automate: In short, change the information flow in business processes. Contemplating its characteristics, it is not difficult to derive potential to improve process efficiency and effectiveness as promised by the real-time enterprise (RTE) visionaries. Non line of sight avoids an object having to be turned several times before the tag can be read, as is often the case with barcode labels. Hence, less manual intervention on the object is required. Tags can still be read when the respective objects are already assembled or integrated in a product. Moreover, multiple reading reduces process lead time. Increased storage capacity allows enhanced product data to be stored on the tag and the ability to add information during an object's life cycle. In combination with sensors, the tag could carry additional up-to-date information about temperature, humidity or pressure in the object's environment [13]. Accurate information and identification increase process transparency, making processes more secure.

But the potential of RFID goes beyond improving the efficiency of existing processes. RFID already enables new products, services and solutions. Application areas are versatile and span various industries. RFID is, for example, used to improve issues in anti-counterfeiting [40], asset/product tracking, industrial warehousing, product handshaking, safety and security, condition monitoring, positioning/locating, and theft or tampering detection [43]. Other examples highlight the potential for completely new services such as enriched museum tours [17].

RFID can enable enterprises to bridge the gap between the real world and its representation in information systems [13], thus paving the road toward the "real time enterprise", promising optimized processes over organizational boundaries, improving decisions through higher data quality, and improving integration of supply chain partners.

\section{Research Model, Hypotheses, and Construct Development}

\subsection{Hypotheses and research model}

Michael Porter describes strategy as "performing different activities from rivals" or "performing similar activities in different ways" and emphasizes that although operational effectiveness is crucial for profitability, it is not strategy [34]. Metro's success in improving operations and cutting cost through RFID [9] and the automotive industry's report about positive return on investments of RFID solutions may not be of a strategic nature yet, but applications are still developing and, as discussed in the previous sections, indeed can enable a company to offer new services not offered by its competitors. Various major consulting firms stress the impact of RFID on strategy. According to Gartner Research, RFID could not only revolutionize the way items are tagged and traced through distribution channels, but also hold "great potential for reshaping business strategies" [45]. But beyond consultants, vendors, and analysts, what do 
(future) users think? How do CIOs assess the strategic importance of RFID?

Diffusion of innovations theory identifies five attributes of innovations influencing their adoption: relative advantage, compatibility, complexity, trialability and observability [36]. Supposing that adoption will only take place if an individual sees a certain importance or usefulness in an innovation, these factors could also influence the perception of strategic importance of an innovation, in this study, RFID. Trialability is the degree to which an innovation may be experienced. The better the individual understands how the innovation works under his or her conditions, the more likely he or she will be to adopt it. Observability is the degree to which the results of an innovation are visible to others. Although the diffusion of RFID is currently low [23] many companies have launched pilot projects, thus creating a certain trialability. Along with vendor's demonstration projects and other available information, these pilot projects provide observability for others. Consequently we hypothesize:

H1: Experience with RFID positively impacts on the perceived strategic importance of RFID.

Relative advantage is the degree to which an innovation is perceived as being better than the idea it supersedes [36]. A similar approach is taken by Davis in his technology acceptance model (TAM), describing perceived usefulness as a determinant on adoption [10]. Perceived benefits have also proved relevant in Iacovou and Benbasat's study about the adoption of EDI [18] and as well were considered in research conducted by Sharma and Citrus on the adoption of RFID [39]. In this study, relative advantage describes potential benefits and improvement due to RFID in comparison to barcode technology. Hence, Hypothesis 2 addresses the perceived potentials of RFID:

H2: The perception of potentials of RFID positively influences the perceived strategic importance of RFID.

Since wholesalers such as Wal-Mart in the USA, Metro in Germany, or Tesco in the UK, and public authorities such as the US Department of Defense have declared RFID a key technology, we see especially larger companies paying attention to the strategic potentials of RFID. We hypothesize therefore:

H3: Company size positively affects the perceived strategic importance of RFID.

In a recent study, AMR research found that $69 \%$ of respondents planned to evaluate, pilot, or implement RFID. They also forecast a market growth of about 40 $\%$, to be reached within two years [35]. Hypothesis 4 links the above described strategic importance with the willingness to invest.

H4: Perceived strategic importance positively influences the willingness to invest in RFID.

We furthermore assume a significant difference between the perceptions and attitudes of CIOs in Italy and Germany due to their cultural differences as similar findings have been reported from the intercultural application of the Technology Acceptance Model [30]. According to Hofstede [14] culture is defined as a "collective programming of the mind". Culture is generally agreed to be reflected in artifacts such as the symbols, heroes, rituals, and values that are typically learned from the environment. This learning starts at birth and continues throughout a person's life. Culture is widely believed to shape individual values and to affect behavior [14-16, 41].

Different cultural groups may have different conceptions of what leadership should entail, i.e. different leadership prototypes and what may be considered strategically important. Several earlier studies revealed that within Europe various cultural clusters can be distinguished [15]. Koopman et al [24] showed that two broad clusters or patterns of cultural values can be distinguished within Europe, contrasting the North-Western and South-Eastern part of Europe. Within these clusters, differences in leadership prototypes to a certain extent mirror differences in culture.

Since Germany belongs to the North-Western and Italy to the South-Eastern cluster we expect to see significantly different empirical results to the test of the hypotheses in both cultures.

Table 1 summarizes the research hypotheses.

\begin{tabular}{|l|l|}
\hline No. & Description of hypothesis \\
\hline H1 & $\begin{array}{l}\text { Experience with RFID positively impacts on the } \\
\text { perceived strategic importance of RFID. }\end{array}$ \\
\hline H2 & $\begin{array}{l}\text { The perception of potentials of RFID positively } \\
\text { influences the perceived strategic importance of } \\
\text { RFID. }\end{array}$ \\
\hline H3 & $\begin{array}{l}\text { Company size positively affects the perceived } \\
\text { strategic importance of RFID. }\end{array}$ \\
\hline H4 & $\begin{array}{l}\text { Perceived strategic importance positively } \\
\text { influences the willingness to invest in RFID. }\end{array}$ \\
\hline
\end{tabular}

Table 1: Research hypotheses 


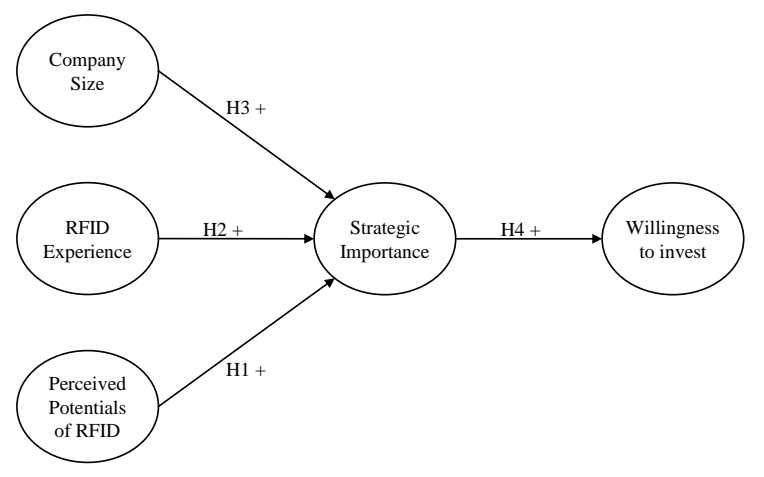

Figure 1: Research model

\subsection{Construct development}

The following table depicts the operationalization of the constructs "company size" (CS), "RFID experience" (EX), "perceived potentials of RFID" (PP), "perceived strategic importance" (SI), and "willingness to invest in RFID" (WI) used in the model.

\begin{tabular}{|c|c|c|}
\hline $\begin{array}{l}\text { Con- } \\
\text { struct }\end{array}$ & Item & Question / Indicator \\
\hline $\mathrm{CS}$ & S14Q14 & $\begin{array}{l}\text { How many employees does the company } \\
\text { have? }\end{array}$ \\
\hline EX & S02Q01 & $\begin{array}{l}\text { How much experience does the company } \\
\text { have with using RFID? }\end{array}$ \\
\hline \multirow[t]{8}{*}{$\mathrm{PP}$} & \multicolumn{2}{|c|}{$\begin{array}{l}\text { Which potentials does RFID have in your opinion? } \\
\text { (5 pt Likert scale from totally disagree - totally agree) }\end{array}$} \\
\hline & S09Q08 & Improve quality \\
\hline & S09Q09 & Automate / reduce manpower \\
\hline & S09Q10 & Reduce errors \\
\hline & S09Q11 & Reduce counterfeits \\
\hline & S09Q12 & Reduce inconsistencies in stock \\
\hline & S09Q15 & Optimize stock keeping \\
\hline & S09Q16 & Improve customer service \\
\hline \multirow[t]{3}{*}{ SI } & S07Q06 & $\begin{array}{l}\text { By using RFID we can gain strategic } \\
\text { advantages. }\end{array}$ \\
\hline & S07Q07 & $\begin{array}{l}\text { RFID has a strategic importance for our } \\
\text { company. }\end{array}$ \\
\hline & S07Q08 & RFID is one of our top IT topics. \\
\hline \multirow[t]{4}{*}{ WI } & S07Q09 & $\begin{array}{l}\text { RFID helps us to build up new core } \\
\text { competencies. }\end{array}$ \\
\hline & S07Q10 & $\begin{array}{l}\text { RFID helps us to use our current core } \\
\text { competencies in a better way. }\end{array}$ \\
\hline & S08Q01 & $\begin{array}{l}\text { In general, I would endorse the } \\
\text { implementation of RFID. }\end{array}$ \\
\hline & S08Q02 & RFID is a topic we will invest in. \\
\hline
\end{tabular}

Table 2: Operationalization of constructs

\subsection{Data collection}

The theoretical framework in Figure 1 has been operationalized and transferred into a structural equation model. Each construct is represented by a set of indicators, i.e. questions in a questionnaire, which were measured on a 5-point Likert scale. Whenever possible, existing measures from prior studies were adopted and adapted to the context of this research.

As unit of analysis top IT decision makers from two countries - Germany and Italy - were chosen. From November 2005 to January 2006, 3171 top IT executives from various industries in Germany were invited to participate in an online survey by a personal letter containing a personal unique access code for the survey website. From April to June 2006, the same survey was conducted in Italy and 2820 top IT executives from various industries in Italy were invited to participate in an online survey by a personal letter containing a personal unique access code for the survey website. We received 463 usable questionnaires from Germany and 157 questionnaires from Italy.

\section{Survey Results}

\subsection{Demographics}

In total, 463 companies of various industries and company sizes took part in the survey (return rate $14.6 \%$ ) in the German sample. The industry most represented was manufacturing (36.9\%), other relevant industry groups were automotive $(18.4 \%)$, services $(16.0 \%)$, retail $(14.3 \%)$, consumer goods $(11.7 \%)$, IT (11.7\%), transport / logistics (11.0\%), pharmaceuticals / healthcare (8.4\%) and other (22.9\%). Companies with less than 2500 employees represented almost $75 \%$ of the participating organizations. Most respondents are CIOs (72 \%). In Italy, 157 IT decision makers participated in the survey, of which all but one were male. The age group 31-50 had the highest representation $(69.2 \%)$. Asked for the main business activities of their company, participants indicated retail (45.2\%), consumer goods (21.7\%), manufacturing (21.7\%), transport / logistics (15.9\%), automotive (10.8\%), pharmaceutics / healthcare (7.0\%), IT (3.8\%), other $(9.6 \%)$. Company sizes measured in number of employees varied; the majority $(75.8 \%)$ had less than 250 employees, $19.1 \%$ had between 250 and 1000 employees, $3.8 \%$ between 1000 and 10000 and $1.3 \%$ exceeded 10000 employees. Most respondents were chief information officers (CIO) (50.2\%) or chief executive officers (11.9\%).

\subsection{Model validation}

This section presents the results of the model test, including the test of the measurement model as well as the structural model. The research model was operationalized and transferred into a structural equation model (SEM) to be analyzed with the PLS 
approach [6, 44]. PLS is particularly suitable if a more explorative analysis close to the empirical data is preferred. To our knowledge, there is no strong theoretical foundation or even empirical evidence on the interplay of company size, RFID experience, perceived potentials of RFID and perceived strategic importance as well as willingness to invest in RFID. Thus rendering an explorative approach seems to be most appropriate.

\subsubsection{Formative measurement model}

In our model, the construct "perceived potentials of RFID" has been operationalized in formative mode since the indicators meet the criteria put forth in [19] for formative measurement models. According to the findings of [11] and [6] five critical issues determining the quality of the measurement model have to be investigated: (1) content specification, (2) indicator specification, (3) indicator reliability, (4) indicator collinearity and (5) external validity.

Content specification consists of defining the scope of the latent constructs to be measured. This is of particular importance, as within formative models the indicators form the latent variable. "The breadth of definition is extremely important to causal indicators" [31], because "failure to consider all facets of the construct will lead to an exclusion of relevant indicators" [11]. The research model presented in this paper includes one latent constructs to be measured with formative indicators: perceived potentials of RFID. This construct was precisely defined and its domain intensively discussed, ensuring the proper specification of the applicable content of all the constructs deployed.

Indicator specification comprises the identification and definition of indicators which constitute the latent constructs. As the aggregation of all formative indicators defines the scope of the formatively measured latent variable, indicator specification is particularly important for models using formative indicators [11]. The indicators used in this model were identified by intensive literature review and have been validated through more than 20 in-depth expert interviews with German and Italian IT executives who were knowledgeable about the topic of this research. Following their input, some initial indicators have been altered to become more precise and understandable to the target audience.

Indicator reliability analyzes the importance of each individual indicator that forms the relevant construct. Two quantitative arguments have to be accounted for: (1) the sign of the indicator needs to be correct as hypothesized and (2) the weighting of the indicator should be at least 0.1 as proposed by [38]. The analysis revealed that three indicators in the German sample did not fulfill these requirements. In the Italian sample two other indicators showed incorrect signs. Although eliminating indicators which do not fulfill the set criteria is recommended by [38], all indicators were kept in the model since it emphasizes the differences in both data samples explaining different perceived potentials in Germany and Italy (see section group analysis and appendix for full figures). Because formative measurement models are based on multiple regression, substantial indicator collinearity would affect the stability of indicator coefficients [11]. In this study, multicollinearity among the indicators used did not pose a problem. The maximum variance inflation factor was far below the common cut-off threshold of 10 [8]. Therefore, no further indicators needed to be rejected as no redundancy was identified.

External validity ensures the suitability of the deployed indicators and is of special importance for formative measurement models if indicators needed to be eliminated. External validity shows the extent to which formative indicators actually capture the construct [6]. Following Diamantopoulos and Winklhofer [11], external validity can be tested by using nomological aspects linking the formative construct with another construct to be expected as antecedent or consequence. As the path coefficient for H1 shows a substantial impact of "perceived potentials of RFID" on strategic importance at a significance level of 0.001 in both data samples, the formative operationalization of the construct is supported.

\subsubsection{Reflective measurement model}

The quality of the measurement model is determined by (1) convergent validity, (2) construct reliability and (3) discriminant validity [3, 4, 7, 32].

Convergent validity is analyzed by indicator reliability and construct reliability [32]. Indicator reliability was examined by looking at the construct loadings. In the model tested, all loadings are significant at the 0.001 level and above the recommended 0.7 parameter value (significance tests were conducted using the bootstrap routine). Construct reliability was tested using two indices: (1) the composite reliability (CR) and (2) the average variance extracted (AVE). Estimated indices were above the threshold of 0.6 for CR [5] and 0.5 for AVE [6] in both data samples (see appendix).

Discriminant validity of the construct items can be analyzed by looking at the cross-loadings. As depicted in the appendix, the loading of each indicator is higher for the respective construct than for any other construct. Therefore, the indicators of different constructs are not related to each other and discriminant validity is shown for both data samples. 


\subsubsection{Structural Model}

The adequacy of indicators in the measurement model enables one to evaluate the explanatory power of the entire model as well as the predictive power of the independent variables. The explanatory power is examined by looking at the squared multiple correlations $\left(\mathrm{R}^{2}\right)$ of the dependent variables. $26.9 \%$ (German sample) and $54.4 \%$ (Italian sample) of the variance in strategic importance is explained by the three independent variables. The $\mathrm{R}^{2}$ of willingness to invest $\left(\mathrm{R}^{2}=0.660\right.$ German sample; $\mathrm{R}^{2}=0.665$ Italian sample) is also encouragingly high. Figure 2 shows that all dependent variables are well explained by their independent variables and therefore pass critical examination.

Predictive power is tested by examining the magnitude of the standardized parameter estimates between constructs together with the corresponding level of significance. Only one path coefficient in the German and two in the Italian sample do not exceed the recommended 0.2 level [6]: company size, RFID experience (Italian sample). Boot-strapping revealed strong significance (at the 0.01 or even 0.001 level) of all dependent variables except for company size and RFID experience in the Italian sample (n.s.). Analysis of the overall effect size $\mathrm{f}^{2}[6,8]$ reveals that "perceived potentials" has a strong effect on "strategic importance" as well as "strategic importance" on "willingness to invest". Weak impact has been shown for the effect of company size and RFID experience on strategic importance in both data samples. Figure 2 depicts the findings graphically.

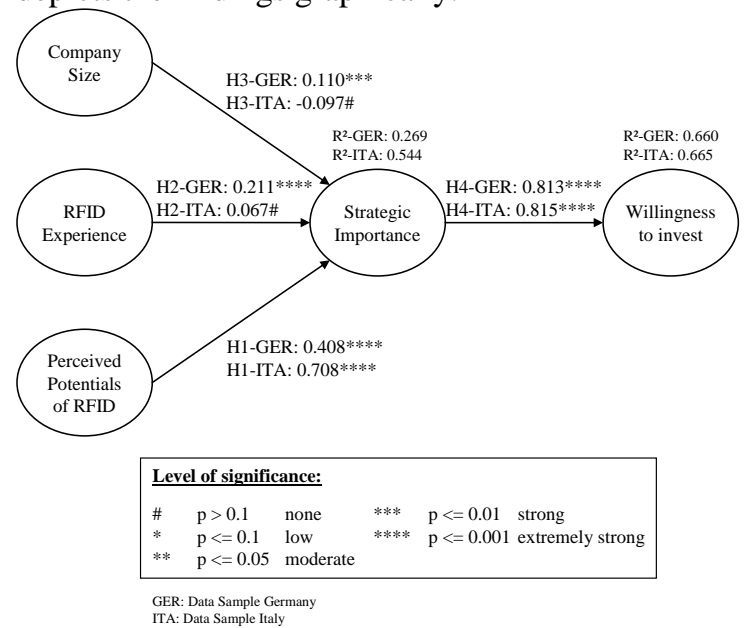

Figure 2: Structural Model Findings

\section{Analysis and Discussion of Results}

RFID is not very widespread neither in Germany [23] nor in Italy [22]. The importance of RFID will rise significantly over the next few years in both countries.
However, RFID is not judged as a strategic issue, nor is it a topic of high priority on the IT agenda. The highlevel concepts often associated with RFID in the media or in consulting, above all the "real time enterprise" or the "internet of things", have not yet found their way into companies' RFID visions. Even though companies' RFID budgets will rise over the next 5 years and IT decision makers are willing to invest in the technology.

\subsection{Key findings of the Overall Model}

Overall findings reveal that perceived potentials of RFID have a significant impact on the perceived strategic importance of RFID. Furthermore, the perception of this strategic importance has a major impact on the intention of IT decision makers to invest in RFID - regardless of the cultural context.

Contradictory to our assumptions and findings in the literature, in our study company size does not influence the perceived strategic importance of RFID. The experience with RFID has an impact on strategic importance of RFID although only in the German context. Although these findings are true for both countries we found significant differences in both groups.

\subsection{Group Analysis}

Drawing from research on the impact of different cultural contexts $[15,24,30]$ we found significant differences of perceived strategic importance and also in the composition of perceived potentials in both cultural settings, Germany and Italy (see Table 4).

In Germany, strategic importance is heavily influenced by the experience with RFID and the potentials attributed to RFID. These potentials are improving quality, automating manpower, reducing counterfeits, and improving customer service (see appendix Table 4). In contrast, Italian CIOs assign the potentials of reducing inconsistencies in stock, optimizing stock keeping, and improving customer service to RFID (see appendix Table 4). In the Italian context, experience with RFID does not influence the perceived strategic importance at all. This finding can be explained by the fact that Italian CIOs have less experience with RFID compared to German CIOs. Thus, this factor cannot explain different influences the perception of the strategic relevance of RFID.

Overall, findings show that perceived potentials have a much larger impact on strategic importance in the Italian context compared to the German context. This finding is contrasted by the result that experience with RFID has almost no impact in the Italian context 
compared to the German context (see Figure 2 and Table 4). Although company size hardly has an impact on the perceived strategic importance in both cultures, the difference between Germany and Italy is significant (see Table 3). While company size has a minor impact on strategic importance in Germany, in Italy it seems to play an almost negligible role. The impact of perceived strategic importance on the willingness to invest in RFID does also not differ significantly - it is extremely high in both cultures (see Table 3 ).

\begin{tabular}{|l|c|c|c|}
\hline Sample Germany vs. Italy & t-value & $\begin{array}{c}\text { Degrees of } \\
\text { freedom } \\
\text { (df) }\end{array}$ & $\begin{array}{c}\text { Level of } \\
\text { Significance }\end{array}$ \\
\hline Company Size $\rightarrow$ Strategic Importance & 2.33 & 620 & 0.05 \\
\hline $\begin{array}{l}\text { RFID Experience } \rightarrow \text { Strategic } \\
\text { Importance }\end{array}$ & 1.36 & 620 & $>0.1$ \\
\hline $\begin{array}{l}\text { Perceived Potentials } \rightarrow \text { Strategic } \\
\text { Importance }\end{array}$ & -3.04 & 620 & 0.01 \\
\hline $\begin{array}{l}\text { Strategic Importance } \rightarrow \text { Willingness to } \\
\text { Invest }\end{array}$ & -0.04 & 620 & $>0.1$ \\
\hline
\end{tabular}

Table 3: Level of significance for group samples Germany vs. Italy

\subsection{Limitations}

The surprisingly strong results certainly need some words of caution that render our findings strictly exploratory and preliminary. Our data is limited as we have been able to analyze the causes of company size, RFID experience, and perceived potentials at one point of time only. This does not necessarily reflect the longterm situation, especially since RFID is such a volatile and emerging IT topic. For example, as the experience with RFID will rise among Italian CIOs, its impact on strategic importance might become much higher and also the attributes of perceived potentials are likely to change over time. Also the finding that company size does not seem to matter as a factor influencing the perceived strategic importance might alter over time as it has to be observed if RFID will become a technology for all kinds of enterprises regardless of size and industry.

\section{Conclusion and Outlook on Further Research}

Gathering empirical insights from 463 German and 157 Italian CIOs this study presented IT decision makers' views of RFID across industries and companies of varying sizes in two countries. The respondents indicated that RFID diffusion is very low. Many IT decision makers have heard about, taken an interest in it, but are still far from implementation.

The opinion on the strategic importance of RFID is divided. The judgments seem to be influenced by the experience with RFID, company size and perceived potential of the technology. Results revealed that the potentials attributed to RFID differ significantly in different cultures. A desire for quality improvement, reduction or automation of manpower, reduction of counterfeits as well as an improvement of customer service were characteristics that most attracted German CIOs to RFID; whereas Italian CIOs mostly associated a reduction of inconsistencies in stock, optimization of stock keeping, and an improved customer service with RFID. A major finding was also the fact that due to little experience among Italian CIOs, this factor hardly influenced the perception of strategic relevance of RFID.

As expected, a higher perception of strategic importance correlated positively and strongly with a higher willingness to invest in the technology in both cultural contexts. However, RFID is not (yet) a topic of high priority on a company's IT agenda. The high-level concepts often associated with RFID in the media or in consulting, above all the "real time enterprise" or the "internet of things" have not yet found their way into RFID visions. A large number of respondents did not indicate that it was necessary to define a vision. On the other hand, virtually all participants stated that the importance of tracking \& tracing and RFID will rise significantly over the next years. The technology might well turn out to be a sleeping giant.

Analyzing the innovation leaders in RFID in the German market in follow-up interviews and case studies (Metro and DHL) our findings were in accordance with those of previous research [28]. For example, if RFID is considered strategically, it can help to increase process efficiencies and provides a significant competitive advantage from the use of RFID data as claimed by consultants in the context of the real-time enterprise (RTE). Furthermore, responses indicated that companies were very interested in building up and improving technical and management skills to be able to redesign infrastructures, processes and organizational structures in order to leverage the potential of real-time infrastructures. Furthermore, they stated (as also reported in other related research [21, 27]) that migration to a real-time enterprise (RTE) requires a continuous migration process and they are convinced that these RFID-enabled RTE-Systems have all necessary attributes of IT-dependent strategic initiatives [33] to be able to deliver a sustainable competitive advantage.

Based on the results of the research, the following insights can be derived:

- RFID is a logical next step in enterprise computing and extending corporate boundaries.

- There is nothing really new about RFID.

- RFID can create a competitive advantage. 
- The degree of experience with RFID is still low among IT decision makers.

- In the current status of RFID company size does not make a difference on the perceived strategic importance attributed to RFID.

- The interplay of perceived strategic importance of RFID and the willingness of IT decision makers to invest in this technology is strong.

- Potentials of RFID are diversified and also perceived differently in different cultures and according to a different level of experience with this new technology.

\subsection{Recommendations for Potential RFID Users}

Companies should look beyond the technology level when dealing with RFID. It will not only be a new technology to replace an old one, but will affect many more processes, products, and services. For many companies, instant action is not necessary. But as RFID's importance is on the rise, companies are well advised to keep watch of the RFID activities of business partners or other relevant stakeholders. As in the case of retail, where Wal-Mart or Metro demanded RFID application from their suppliers, or in pharmaceutics where the US Food and Drug Administration recommended RFID to prevent counterfeiting, companies may be forced to react quickly. Instead of acting just because of forced compliance, companies should explore how RFIDenabled solutions could generate competitive advantage if properly integrated into their IT strategy.

Companies might want to gain technical, economical and organizational RFID experience by moving along with (1) isolated, closed loop internal asset management processes on pallet/carton level; (2) Open loop cross-enterprise asset management on pallet level; (3) Item-based solutions as products and services.

\subsection{Recommendations for RFID Vendors}

RFID vendors should not underestimate the complexity of the RFID topic. Customers appreciate the operative benefits that might be achieved through this technology, but they do not link it to abstract, possibly strategic long-term concepts such as real time enterprise. Vendors must improve their way of communicating RFID as an enabler for these visions and explain its impact on IT processes and IT strategy if they want to convince customers that RFID is more than just another technology. Our study showed that the potentials and benefits associated with RFID differ significantly in cultural contexts. A clear and adapted market communication is thus necessary to address target users and their needs appropriately.

\subsection{Further Research}

Future research should analyze the diffusion of RFID and the corresponding strategic paradigm shifts towards real time enterprises on a longitudinal level and contrast it to the diffusion of other complex IT concepts such as ERP or EDI. There is need for theoretical concepts and models that help understand, identify, design, deliver and exploit potentially disruptive IT-dependent strategic initiatives that deliver sustainable competitive advantages. Especially in the context of multi-national enterprises analyses of the role of different cultural backgrounds of decision makers and corporate cultures might provide fruitful insights as we found first antecedents of such cultural differences. Further work should also attempt to determine strategic importance as a construct of different aspects instead of asking for it directly. Moreover, it should examine further factors that may take influence on the perceived strategic importance of RFID and intermediating variables as well as causal relationships. Additionally more in-depth insights on risks and success factors of how to systematically leverage the potentials of RFID and consequently the real-time enterprise are needed.

\section{Appendix}

\begin{tabular}{|c|c|c|c|c|c|c|c|c|c|}
\hline \multirow[b]{2}{*}{ Construct } & \multirow[b]{2}{*}{ Item } & \multicolumn{4}{|c|}{ Sample Germany $(n=463)$} & \multicolumn{4}{|c|}{ Sample Italy (n=157) } \\
\hline & & $\begin{array}{l}\text { Load. / } \\
\text { Weight }\end{array}$ & Sign. & CR & AVE & $\begin{array}{l}\text { Load. / } \\
\text { Weight }\end{array}$ & Sign. & CR & AVE \\
\hline $\begin{array}{l}\text { Company } \\
\text { Size } \\
\text { Reflective }\end{array}$ & S14Q14 & 1.00 & - & 1.00 & 1.00 & 1.00 & - & 1.00 & 1.00 \\
\hline $\begin{array}{l}\text { RFID Expe- } \\
\text { rience } \\
\text { Reflective }\end{array}$ & S02Q01 & 1.00 & - & 1.00 & 1.00 & 1.00 & - & 1.00 & 1.00 \\
\hline \multirow{7}{*}{$\begin{array}{l}\text { Perceived } \\
\text { Potentials } \\
\text { Formative }\end{array}$} & S09Q08 & 0.448 & 0.001 & & & 0.273 & $>0.1$ & & \\
\hline & S09Q09 & 0.279 & 0.05 & & & -0.258 & $>0.1$ & & \\
\hline & S09Q10 & 0.098 & $>0.1$ & & & 0.125 & $>0.1$ & & \\
\hline & S09Q11 & 0.256 & 0.05 & & & -0.210 & $>0.1$ & & \\
\hline & S09Q12 & -0.018 & $>0.1$ & & & 0.415 & 0.05 & & \\
\hline & S09Q15 & 0.027 & $>0.1$ & & & 0.416 & 0.05 & & \\
\hline & S09Q16 & 0.429 & 0.001 & & & 0.406 & 0.1 & & \\
\hline \multirow{3}{*}{$\begin{array}{l}\text { Strategic } \\
\text { Importance } \\
\text { Reflective }\end{array}$} & S07Q06 & 0.861 & 0.001 & \multirow[t]{3}{*}{0.910} & \multirow[t]{3}{*}{0.771} & 0.887 & 0.001 & \multirow[t]{3}{*}{0.919} & \multirow[t]{3}{*}{0.792} \\
\hline & S07Q07 & 0.917 & 0.001 & & & 0.899 & 0.001 & & \\
\hline & S07Q08 & 0.856 & 0.001 & & & 0.884 & 0.001 & & \\
\hline \multirow{4}{*}{$\begin{array}{l}\text { Willingness } \\
\text { to Invest } \\
\text { Reflective }\end{array}$} & S08Q01 & 0.803 & 0.001 & \multirow[t]{4}{*}{0.901} & \multirow[t]{4}{*}{0.694} & 0.892 & 0.001 & \multirow[t]{4}{*}{0.935} & \multirow[t]{4}{*}{0.782} \\
\hline & S08Q02 & 0.847 & 0.001 & & & 0.891 & 0.001 & & \\
\hline & \begin{tabular}{|l|} 
S07Q09 \\
\end{tabular} & 0.796 & 0.001 & & & 0.876 & 0.001 & & \\
\hline & S07Q10 & 0.881 & 0.001 & & & 0.878 & 0.001 & & \\
\hline
\end{tabular}

Table 4: Indicator and Construct Reliability for both data samples 


\begin{tabular}{|l|l|l|l|l|}
\hline \multirow{2}{*}{ Item } & \multicolumn{4}{|c|}{ Construct } \\
\cline { 2 - 5 } & $\begin{array}{l}\text { Strategic } \\
\text { Impor- } \\
\text { tance }\end{array}$ & $\begin{array}{l}\text { Willing- } \\
\text { ness to } \\
\text { Invest }\end{array}$ & $\begin{array}{l}\text { Expe- } \\
\text { rience } \\
\text { RFID }\end{array}$ & $\begin{array}{l}\text { Company } \\
\text { Size }\end{array}$ \\
\hline S14Q14 & 0.218 & 0.211 & 0.320 & 1.000 \\
\hline S02Q01 & 0.296 & 0.269 & 1.000 & 0.320 \\
\hline S08Q01 & 0.622 & 0.804 & 0.202 & 0.232 \\
\hline S08Q02 & 0.711 & 0.847 & 0.315 & 0.246 \\
\hline S07Q09 & 0.664 & 0.796 & 0.153 & 0.053 \\
\hline S07Q10 & 0.706 & 0.882 & 0.232 & 0.174 \\
\hline S07Q06 & 0.860 & 0.723 & 0.235 & 0.186 \\
\hline S07Q07 & 0.917 & 0.739 & 0.274 & 0.200 \\
\hline S07Q08 & 0.856 & 0.677 & 0.264 & 0.185 \\
\hline
\end{tabular}

Table 5: PLS Crossloadings of reflectively measured constructs for sample Germany

\begin{tabular}{|l|l|l|l|l|}
\hline \multirow{2}{*}{ Item } & \multicolumn{4}{|c|}{ Construct } \\
\cline { 2 - 5 } & $\begin{array}{l}\text { Strategic } \\
\text { Impor- } \\
\text { tance }\end{array}$ & $\begin{array}{l}\text { Willing- } \\
\text { ness to } \\
\text { Invest }\end{array}$ & $\begin{array}{l}\text { Expe- } \\
\text { rience } \\
\text { RFID }\end{array}$ & $\begin{array}{l}\text { Company } \\
\text { Size }\end{array}$ \\
\hline S14Q14 & -0.043 & 0.001 & 0.101 & 1.000 \\
\hline S02Q01 & 0.353 & 0.408 & 1.000 & 0.101 \\
\hline S08Q01 & 0.758 & 0.892 & 0.384 & 0.105 \\
\hline S08Q02 & 0.800 & 0.890 & 0.290 & 0.036 \\
\hline S07Q09 & 0.611 & 0.877 & 0.314 & -0.078 \\
\hline S07Q10 & 0.688 & 0.879 & 0.440 & -0.086 \\
\hline S07Q06 & 0.888 & 0.794 & 0.349 & -0.129 \\
\hline S07Q07 & 0.899 & 0.708 & 0.312 & 0.120 \\
\hline S07Q08 & 0.884 & 0.666 & 0.261 & -0.107 \\
\hline
\end{tabular}

Table 6: PLS Crossloadings of reflectively measured constructs for sample Italy

\section{References}

[1] Agarwal, V. (2001) Assessing the Benefits of Auto-ID Technology in the Consumer Goods Industry, Cambridge Auto-ID Lab, Cambridge.

[2] Asif, Z., and Mandviwalla, M. (2005) Integrating the supply chain with RFID: A technical and business analysis, Communications of AIS, 15, 393-427.

[3] Bagozzi, R.P. (1979) "The Role of Measurement in Theory Construction and Hypothesis Testing: Toward a Holistic Model," in: O.C. Ferrell, S.W. Brown and C.W. Lamb (eds.) Conceptual and Theoretical Developments in Marketing, Chicago, 15-32.

[4] Bagozzi, R.P., and Phillips, L. (1982) Representing and Testing Organizational Theories: A Holistic Construal, Administrative Science Quarterly, 27, September, 459-489.
[5] Bagozzi, R.P., and Yi, Y. (1988) On the Evaluation of Structural Equation Models, Journal of the Academy of Marketing Science, 16, 74-94.

[6] Chin, W.W. (1998) "The Partial Least Squares Approach to Structural Equation Modeling," in: G.A. Marcoulides (ed.) Modern Business Research Methods, Lawrence Erlbaum Accociates, Mahwah, NJ, 295-336.

[7] Churchill, G. (1979) A Paradigm for Developing Better Measures of Marketing Constructs, Journal of Marketing, 16, February, 64-73.

[8] Cohen, J. (2003) Applied multiple regression/correlation analysis for the behavioral sciences, Lawrence Erlbaum Associates, London.

[9] Collins, J. "Metro Group Reaps Gains From RFID " in: RFID-Journal, 2005.

[10] Davis, F.D. (1989) Perceived Usefulness, Perceived Ease of Use and User Acceptance of Information Technology, MIS Quarterly, September 1989, 319-339.

[11] Diamantopoulos, A., and Winklhofer, H.M. (2001) Index Construction with Formative Indicators: An Alternative to Scale Development, Journal of Marketing Research, 38, May, 269-277.

[12] Finkenzeller, K. (2003) RFID handbook: fundamentals and applications in contactless smart cards and identification, Wiley, Chichester.

[13] Haller, S., and Hodges, S. (2002) The Need for a Universal SmartSensor Network, Univeristy of Cambridge, Cambridge.

[14] Hofstede, G. (1984) Culture's Consequences: International Differences in Work-Related Values, Sage, Beverly Hills.

[15] Hofstede, G. (1991) Cultures and Organizations: Software of the Mind, McGrawHill, London.

[16] Hofstede, G. (2006) What did GLOBE really measure? Researchers' minds versus respondents' minds, Journal of International Business Studies, 37, 6, 882-896.

[17] Hsi, S., and Fait, H. (2005) RFID enhances visitors' museum experience at the Exploratorium, Communications of the ACM, $48,9,60-65$.

[18] Iacovou, C., and Benbasat, I. (1995) Electronic Data Interchange and Small Organizations: Adoption and Impact of Technology, MIS Quarterly, 19, 465-485.

[19] Jarvis, C.B., MacKenzie, S.B., and Podsakoff, P.M. (2003) A Critical Review of Construct 
Indicators and Measurement Model Misspecification in Marketing and Consumer Research, Journal of Consumer Research, 30, 2, 199-218.

[20] Karkkainen, M. (2003) Increasing efficiency in the supply chain for short shelf life goods using RFID tagging, International Journal of Retail \& Distribution Management, 31, 10, 529.

[21] Khosla, V., and Pal, M. (2002) Real Time Enterprises: A Continuous Migration Approach, Information Knowledge Systems Management, $3,1,53$.

[22] Knebel, U., Leimeister, J.M., and Krcmar, H. (2006) Strategic Importance of RFID - the Perspective of IT Decision Makers in Italy, Journal of Information Technology Management, 17, 4, 1-11.

[23] Knebel, U.F., Leimeister, J.M., and Krcmar, H. (2007) Potentials of Tracking and Tracing Technologies - The Perspective of IT Decision Makers in Germany, University of St. Gallen, Proceedings of the Proceedings of the 15th European Conference on Information Systems (ECIS2007), June 7-9 2007, St. Gallen, Switzerland, St. Gallen, 2007, 1766-1777.

[24] Koopman, P.L., Hartog, D.N.D., Konrad, E., and al, e. (1999) National Culture and Leadership Profiles in Europe: Some Results From the GLOBE Study, European Journal of Work \& Organizational Psychology, 8, 4, 503520.

[25] Landt, J. (2005) The History o RFID, IEEE Potentials, 24, 4, 8-11.

[26] Lee, Y.M., Cheng, F., and Leung, Y.T. (2004) Exploring the impact of RFID on supply chain dynamics, IEEE, Proceedings of the Simulations Conference, 2004.

[27] Leimeister, J.M., Knebel, U., and Krcmar, H. (2007) RFID as enabler for the boundless realtime organisation: empirical insights from Germany, International Journal of Networking and Virtual Organisations (INJVO), 4 1, 45-64.

[28] Loebbecke, C., and Palmer, J. (2006) RFID in the Fashion Industry:Kaufhof Department Stores AG and Gerry Weber International AG, Fashion Manufacturer, MIS Quarterly Executive, 5, 2, 69-79.

[29] Luftman, J., Kempaiah, R., and Nash, E. (2006) Key Issues for IT Executives 2004 MIS Quarterly Executive, 5, 2, 27-45.

[30] McCoy, S., Galletta, D., and King, W.R. (2007) Applying TAM across cultures: the need for caution, European Journal of Information Systems, 16, 1, 81-90.
[31] Nunnally, J.C., and Bernstein, I.H. (1994) Psychometric Theory, (3rd. ed.), McGraw-Hill, New York.

[32] Peter, J. (1981) Reliability: A Review of Psychometric Basics and Recent Marketing Practices, Journal of Marketing Research, 16, February, 6-17.

[33] Piccoli, G., and Ives, B. (2005) Review: ITdependent strategic initiatives and sustained competitive advantage: A review and synthesis of the literature, MIS Quarterly, 29, 4, 747-776.

[34] Porter, M.E. (1996) What is Strategy?, Harvard Business Review, 74, Nov./Dec, 61-78.

[35] Reilley, K. (2005) AMR Research Survey Finds $69 \%$ of Respondents Plan to Evaluate, Pilot, or Implement RFID in 2005, [online], available from Internet Source http://www.amrresearch.com/Content/ View.asp?pmillid=18470, accessed 14.6.2007.

[36] Rogers, E.M. (1995) Diffusion of Innovations, (4. ed.), The Free Press, New York.

[37] Sarma, S. (2004) Integrating RFID, Queue, 2, 7 , 50-57.

[38] Seltin, N., and Keeves, J.P. (1994) "Path Analysis with Latent Variables," in: T. Husen and T.N. Postlethwaite (eds.) International Encyclopedia of Education, Oxford, 4352-4359.

[39] Sharma, A., and Citurs, A. "Radio Frequency Identification (RFID) Adoption Drivers - A radical Innovation Adoption Perspective," in: Eleventh Americas Conference on Information Systems, AIS, Omaha, 2005.

[40] Staake, T., Thiesse, F., and Fleisch, E. (2005) Extending the EPC network: the potential of RFID in anti-counterfeiting ACM, Proceedings of the ACM symposium on Applied computing Santa Fe, 2005, 1607-1612.

[41] Straub, D., Keil, M., and Brenner, W. (1997) Testing the technology acceptance model across cultures: A three country study, Information \& Managament, 33, 1, 1-11.

[42] Want, R. (2004) The magic of RFID, Queue, 2, 7, 40-48.

[43] Wilding, R., and Delgado, T. "RFID Demystified: Supply-Chain Applications," in: Logistics \& Transport Focus, Chartered Institute of Logistics \& Transport (UK), 2004, p. 42.

[44] Wold, H. (1985) Partial Least Squares, Wiley, New York.

[45] Woods, J., Peterson, K., and Hirst, C. "Maturing Open RFID Applications Will Reshape SCM," Gartner Research, Stanford. 